\title{
JIMMBA
}

Jurnal IImiah Mahasiswa Manajemen, Bisnis dan Akuntansi

Homepage: http://journal.stieputrabangsa.ac.id/index.php/jimmba/index

\section{Analisis Game Theory pada Strategi Bersaing Alfamart dan Indomaret di Kebumen}

\author{
An Nisa Nur Laila', Kabul Trifiyanto ${ }^{2}$ \\ 1,2 Sekolah Tinggi Ilmu Ekonomi Putra Bangsa \\ Email: fadhilnisa1@gmail.com ${ }^{1}$
}

\section{ARTICLE INFO}

Article History:

Received: April 14 2021

Accepted: April 26 2021

Published: May $6^{\text {th }} 2021$

Keywords:

Marketing Strategies,

Game Theory,

Importance Performance

Analysis

\begin{abstract}
Alfamart and Indomaret are the market rulers in Indonesia. According to research firm Nielsen, Alfamart and Indomaret take 87\% market share (Gumiwang, 2019). Both retailers compete in opening their outlets which can influence marketing strategies and increase sales volume. This study aims to determine the optimal marketing strategy through game theory that is oriented towards the advantages of company facilities that are prioritized by customers and to find out what strategies are appropriate to be improved and maintained so that customers are more satisfied. Using the SPSS 24 Version tool to calculate the level of validity and reliability of each attribute given and also to determine a Cartesian chart to determine Importance Performance Analysis and use the POM-QM 4 software to determine what strategy is superior to Alfamart and Indomaret. The elements of the marketing mix used are Product, price, Promotion, Place, People, physical evidence and process. The purpose of this research is to get an optimal marketing strategy through game theory that is oriented to the advantages of company facilities that are prioritized by customers and to find out what strategies are appropriate to improve so that customers are more satisfied. The results showed that Alfamart was superior in implementing promotion strategies and Indomaret was superior in implementing product strategies.
\end{abstract}

\section{Pendahuluan}

Tujuan utama pemasaran adalah menjual, mendistribusikan barang ke tangan pelanggan dan memeroleh laba untuk menunjang kontinuitas dan membiayai pengeluaran perusahaan. Mewujudkan pemasaran yang sukses tidak dapat dipisahkan dari kemampuan manajemen perusahaan untuk mengelola dan mengoordinasikan secara tepat marketing mix. Strategi marketing mix perlu digunakan pada bisnis yang berhubungan langsung dengan pelanggan akhir. Pengelolaan ritel harus mengikuti perkembangan teknologi pemasaran agar dapat berhasil pemasarannya dan memiliki keunggulan bersaing. (Sunyoto, 2015). 
Berdasarkan studi Brandz Top 50 Most Valuable Indonesian Brand dalam Kontan.co.id tahun 2018 usaha jenis ritel Indomaret, Alfamart menjadi bagian merek yang paling dikenal di domestik dengan performa baik dan pertumbuhan total value dari merek ritel yang tumbuh sekitar 8\% yaitu menjadi 2,9 miliar US Dollar. Indomaret dan Alfamart memiliki performa baik karena strategi ekspansi yang dilakukan dengan meningkatkan jejaring gerai mengejar pertumbuhan. Gencarnya ekspansi toko ritel modern dan persaingan juga terjadi di Kebumen dilihat dari gerai yang dibukanya.

Menurut Sunyoto (2015), kunci memenangkan persaingan adalah memberikan nilai dan kepuasan kepada pelanggan melalui penyampaian jasa yang berkualitas dengan harga yang bersaing. Menurut Kotler (2003), kepuasan pelanggan merupakan ungkapan perasaan seseorang sesudah membandingkan antara produk yang dirasakan dengan yang diharapkan. Apabila kinerja sesuai atau melebihi harapan, maka pelanggan akan merasa puas. Kepuasan dapat diukur dengan beberapa karakteristik salah satunya menggunakan bauran pemasaran (Lupiyoadi dan Hamdani, 2009).

Harapan strategi 7P (product, price, promotion, place, people, physical evidenve dan process) yang diterapkan Alfamart dan Indomaret menjadi acuan perusahaan bagaimana strategi yang tepat digunakan agar pelanggan puas terhadap layanan yang diberikan. Salah satu caranya menggunakan teori permainan (game theory). Untuk memperkirakan strategi pemasaran terbaik yang harus dilakukan, maka perusahaan harus memperkirakan langkah pesaingnya. Dengan metode Importance Performance Analysis untuk memetakan atribut yang perlu diperbaiki untuk meningkatkan kepuasan pelanggan.

\section{Kajian Teori dan Telaah Literatur}

Strategi bersaing perusahan adalah upaya pencarian posisi bersaing yang menguntungkan untuk mempertahankan posisi dan kekuatan yang menentukan posisi perusahaan dalam persaingan bisnis (Kotler dan Amstrong, 2012). Strategi bersaing memiliki kekuatan yang besar untuk membuat perusahaan menjadi lebih baik. Dengan tercapainya tujuan-tujuan strategi bersaing maka perusahaan dapat memperbaiki kualitas yang menguntungkan perusahaan dan mengalahkan persaingan yang ada.

Marketing mix adalah strategi perusahaan untuk merumuskan penawaran produk bagi konsumen dengan memadukan elemen pemasaran (Tjiptono \& Diana, 2016). Penggunaan marketing mix dapat memengaruhi persepsi konsumen sehingga dapat meningkatkan kepuasan. Strategi bauran pemasaran perlu digunakan pada bisnis bisnis ritel (Simatupang, 2003:60). Pengelolaan ritel harus mengikuti perkembangan teknologi pemasaran agar berhasil dan memiliki keunggulan bersaing (Sunyoto, 2015). Marketing mix pada jasa meliputi product, price, promotion, place, people, physical evidence dan process.

Product merupakan konsep objek yang memberikan nilai kepada pelanggan (Lupiyoadi dan Hamdani, 2009). Kualitas produk merupakan sesuatu yang dapat memenuhi kebutuhan yang ditawarkan perusahaan untuk diperhatikan, diminta, digunakan oleh konsumen. Kualitas produk dapat memengaruhi kepuasan konsumen, semakin tinggi tingkat kualitas produk perusahaan, maka semakin tinggi tingkat kepuasan konsumen yang dihasilkan (Kotler dan Keller, 2009: 144). Hasil penelitian yang dilakukan Abbas (2015) menunjukkan 
bahwa product berpengaruh positif terhadap kepuasan konsumen. Hasil penelitian menunjukan adanya hubungan positif antara produk terhadap kepuasan konsumen.

Price merupakan ukuran yang ditukarkan untuk memperoleh hak kepemilikan atau penggunaan produk (Tjiptono \& Diana, 2020). Menurut Kotler \& Amstrong (2006: 48) harga yang terjangkau dan sesuai dengan yang diharapkan konsumen akan meningkatkan kepuasan konsumen. Hasil penelitian yang dilakukan Abbas (2015) menunjukkan bahwa price berpengaruh positif terhadap kepuasan konsumen. Hasil penelitian menunjukan adanya hubungan positif antara harga terhadap kepuasan konsumen.

Promotion bertujuan menginformasikan, memengaruhi, membujuk serta mengingatkan pelanggan sasaran produk (Tjiptono, 2008). Menurut (Foster 2008: 70), promosi penjualan memberikan nilai lebih dan insentif kepada konsumen dalam pembelian di periode tertentu. Bauran promosi terdiri atas iklan, sales promotion, personal selling dan publisitas. Hasil penelitian yang dilakukan Abbas (2015) menunjukkan bahwa promotion berpengaruh positif terhadap kepuasan konsumen. Hasil penelitian menunjukan adanya hubungan positif antara promosi terhadap kepuasan konsumen.

Place merupakan gabungan antara lokasi yang strategis dan keputusan saluran distribusi yaitu cara penyampaian jasa kepada pelanggan (Lupiyoadi dan Hamdani, 2009). Lokasi yang strategis mudah dijangkau, nyaman, aman akan meningkatkan tingkat kepuasan konsumen. Hasil dari penelitian yang dilakukan Abbas (2015) menunjukkan bahwa place berpengaruh paling dominan terhadap kepuasan konsumen. Hasil penelitian menunjukan adanya hubungan positif antara lokasi terhadap kepuasan konsumen.

People berfungsi sebagai penyedia jasa yang memengaruhi kualitas jasa yang diberikan. Service people dengan pelayanan yang baik, cepat, ramah, dan akurat dapat menciptakan kepuasan pada perusahan dan meningkatkan citra baik perusahaan (Adam, 2018). Hasil penelitian yang dilakukan Gultom, et all. (2014) menunjukkan bahwa people berpengaruh positif terhadap kepuasan mahasiswa. Hasil penelitian menunjukan adanya hubungan positif antara SDM terhadap kepuasan konsumen.

Physical Evidence merupakan lingkungan fisik tempat jasa diciptakan dan langsung berinteraksi dengan pelanggan (Lupiyoadi \& Hamdani, 2009). Suasana toko perlu dipertimbangkan untuk memberikan suatu nilai lebih kepada konsumen. Hasil penelitian yang dilakukan Gultom, et all. (2014) menunjukkan bahwa physical evidence berpengaruh positif terhadap kepuasan mahasiswa. Hasil penelitian menunjukan adanya hubungan positif antara bukti fisik terhadap kepuasan konsumen.

Process merupakan aktivitas penyampaian jasa yang diberikan (Lupiyoadi \& Hamdani, 2009). Layanan dengan proses pelayanan di kasir yang cepat, tersedianya fasilitas debit card dapat menciptakan kepuasan konsumen (Ma'ruf, 2005). Hasil penelitian yang dilakukan Gultom, et al (2014) menunjukkan bahwa proses berpengaruh positif pada kepuasan mahasiswa. Hasil penelitian menunjukan hubungan positif antara proses pada kepuasan.

Teori permainan merupakan suatu model matematika yang digunakan dalam situasi persaingan antara pihak yang sedang bersaing. Dalam permainan peserta adalah pesaing. Keuntungan bagi yang satu merupakan kerugian bagi yang lain. Teori permainan pertama kali dikemukakan oleh seorang ahli matematika Prancis yaitu Emile Biorel pada tahun 1921, 
lalu Jhon Von Neemann dan Oskar Morgenstern mengembangkan lebih lanjut sebagai alat untuk merumuskan perilaku ekonomi yang bersaing (Subagyo dkk, 2002).

Penelitian yang dilakukan oleh Yuni, et all. (2018) dengan judul Strategi Pemasaran Warung Kopi di Kota Banda Aceh dengan Game Theory pada Journal of Data Analysis Vol 1, No.2. Populasi penelitian yaitu konsumen pada Solong Coffe, Dhapu Kupi dan Zakir Warkop, dengan jumlah sampel 96 responden ditentukan dengan convening sampling (teknik pengambilan sampel tidak acak). Teknik analisis data game theory menggunakan bantuan software LINDO 6.1. Hasil analisa data yang dilakukan dengan game theory untuk menentukan strategi pemasaran warung kopi yang optimal, kesimpulan yang dapat diambil yaitu: strategi optimal Solong Coffee adalah strategi produk, strategi optimal Dhapu Kupi adalah strategi lokasi, strategi optimal Zakir Warkop adalah strategi sarana fisik.

Penelitian yang dilakukan oleh Imran (2019) dengan judul Penentuan Strategi Pemasaran Jasa Transportasi Online dengan Teori Permainan (Game Theory) untuk Meningkatkan Minat Konsumen di Wilayah Makassar (Studi Kasus Pengguna Go-jek dan Grab) pada Repositori.uin-alauddin.ac.id. Populasi penelitian ini adalah konsumen Grab dan Gojek pada masyarakat Makassar, dengan jumlah sampel 100 responden ditentukan dengan teknik homogen atau jumlah sampel tak terbatas. Teknik analisis game theory dengan bantuan software POM. Hasil analisa data didapatkan bahwa Grab dalam strategi hemat biaya jauh lebih besar dibanding dengan Gojek dengan strategi armada.

Penelitian yang dilakukan oleh Purba (2015) dengan judul Aplikasi Teori Permainan Fuzzy dalam Menentukan Strategi Pemasaran Optimal (Studi Kasus: Persaingan Minimarket Indomaret dan Minimarket Alfamart) Populasi penelitian ini adalah mahasiswa Universitas Sumatera Utara yang menjadi konsumen minimarket Indomaret dan Alfamart di Medan, dengan jumlah sampel 100 responden. Simpulan penelitian tersebut adalah permainan dimenangkan oleh minimarket Indomaret dengan menggunakan strategi kenyamanan berbelanja. Sedangkan untuk meminimumkan kekalahannya, minimarket Alfamart juga menggunakan strategi kenyamanan berbelanja.

\section{Metode Penelitian}

Penelitian kuantitatif deskriptif dengan metode pengumpulan data menggunakan kuisioner. Responden dalam penelitian ini adalah masyarakat Kebumen yang merupakan pelanggan kedua ritel Alfamart dan Indomaret di Kebumen. Oleh karena jumlah populasi tidak diketahui maka metode pengumpulan sampel dilakukan dengan rumus Isac Michael (Siregar, 2017:35), untuk tingkat dengan rumus sebagai berikut:

$$
n=p . q \frac{\left(Z_{\propto / 2}\right)^{2}}{e^{2}}
$$

\section{Keterangan:}

n : jumlah sampel

$\mathrm{p} \quad$ : precisious (batas tetapan presisi $=5 \%$ )

q : quantity (jumlah estimasi $=0,5$ )

$\mathrm{Za} / 2$ : nilai Ztabel $(\mathrm{a}=5 \% ; \mathrm{a} / 2=0,025)$

e :error (batas maksimal error $=10 \%$ ) 
Dari rumus diatas, dapat dihitung jumlah sampel sebagai berikut:

$$
\begin{aligned}
& n=p \cdot q \frac{\left(Z_{\alpha / 2}\right)^{2}}{e^{2}} \\
& n=0,5 \times 0,5\left(\frac{1,96}{0,1}\right)^{2} \\
& \mathrm{n}=96,4
\end{aligned}
$$

Peneliti mengambil sampel sebanyak 100 orang agar dapat memenuhi syarat pengambilan sampel minimal yaitu sebanyak 96 orang.

Analisis data penelitian dilakukan dengan Importance Performance Analysis menggunakan bantuan software SPSS dan analisis game theory dengan menggunakan bantuan software POM-QM for windows.

\section{Hasil dan Pembahasan}

\section{Uji Validitas}

Pengujian validitas menggunakan bantuan SPSS versi 24 dengan $n=100$, derajat kebebasan (df) $=\mathrm{n}-2=98$ dan tingkat signifikansi 5\% maka diperoleh rtabel $=0.1654$ Adapun hasil validitas data kuisioner secara lengkap diberikan pada Tabel 1 berikut ini:

Tabel 1. Hasil Uji Validitas Data Kuisioner

\begin{tabular}{llll}
\hline No & Atribut & R tabel & Keterangan \\
\hline 1 & Product (produk) & 0,788 & Valid \\
2 & Price (harga) & 0,897 & Valid \\
3 & Promotion (promosi) & 0,792 & Valid \\
4 & Place (lokasi) & 0,811 & Valid \\
5 & People (SDM) & 0,857 & Valid \\
6 & Process (proses) & 0,858 & Valid \\
7 & Physical evidence (bentuk fisik) & 0,875 & Valid \\
\hline sumber: data diolah, 2021 & &
\end{tabular}

\section{Uji Reliabilitas}

Dari hasil uji reliabilitas dengan bantuan software SPSS versi 2 diperoleh nilai $a=0.817>0.60$, yang artinya setiap strategi yang digunakan pada kuisioner dinyatakan reliabel 


\section{Diagram Kartesius IPA}

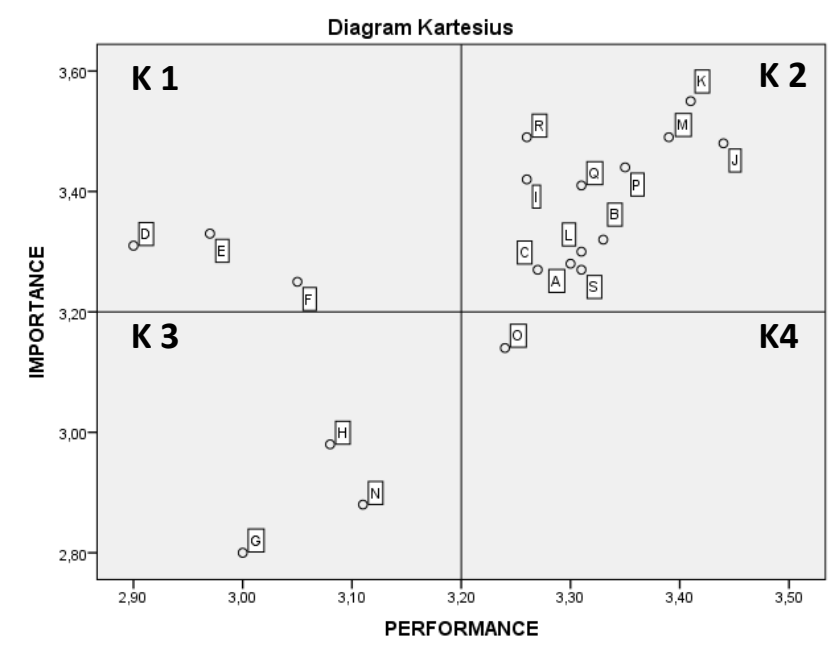

Keterangan

A. Produk yang lengkap jenisnya

B. Produk yang ditawarkan sesuai standar karena telah lolos uji BPOM

C. Produk yang beragam mereknya sesuai dengan kebutuhan pelanggan

D. Keterjangkauan harga

E. Kesesuaian harga dengan kualitas produk

F. Kesesuaian harga dengan manfaat

G. Poin untuk member

H. Keragaman media untuk promosi

I. Diskon atau obral

J. Akses yang mudah dijangkau

K. Ketersediaan tempat parkir

L. Lokasi dekat dengan tempat beraktivitas

M. Pelayanan yang dilakukan karyawan ramah, sopan, cepat tanggap dan akurat

N. Ajakan pelanggan kepada pelanggan lain, tentang kualitas jasa yang pernah didapatkan dari perusahaan

O. Eksterior gerai yang menarik

P. Penempatan barang yang mudah dicari

Q. Pencahayaan dan sirkulasi udara yang baik

R. Proses pelayanan yang cepat

S. Ketersediaan fasilitas debit card

Strategi yang dapat dilakukan berkenaan dengan posisi masing-masing variabel pada keempat kuadran tersebut dapat dijelaskan sebagai berikut:

a. Kuadran 1 (Concentrate These)

Kuadran 1 merupakan wilayah yang memuat faktor-faktor harus ditingkatkan. Memuat atribut keterjangkauan harga; kesesuaian harga dengan kualitas produk; kesesuaian harga dengan manfaat

b. Kuadran 2 (Keep Up the Good Work)

Kuadran 2 merupakan wilayah yang memuat faktor-faktor harus tetap dipertahankan karena semua variabel ini menjadikan produk atau jasa unggul di mata pelanggan. Memuat atribut: produk yang lengkap jenisnya, produk yang ditawarkan sesuai standar 
karena telah lolos uji BPOM, produk yang beragam mereknya sesuai dengan kebutuhan pelanggan, diskon atau obral, akses yang mudah dijangkau, ketersediaan tempat parkir, lokasi dekat dengan tempat beraktivitas, pelayanan yang dilakukan karyawan ramah, sopan, cepat tanggap dan akurat, penempatan barang yang mudah dicari, pencahayaan dan sirkulasi udara yang baik, proses pelayanan yang cepat, ketersediaan fasilitas debit card.

c. Kuadran 3 (Low Priority)

Kuadran 3 merupakan wilayah yang memuat faktor-faktor yang pengaruhnya terhadap manfaat yang dirasakan oleh pelanggan sangat kecil. Memuat atribut: poin untuk member; keragaman media untuk promosi; ajakan pelanggan kepada pelanggan lain, tentang kualitas jasa yang pernah didapatkan dari perusahaan.

d. Kuadran 4 (Possible Overkill)

Kuadran 4 merupakan wilayah yang memuat faktor-faktor dapat dikurangi agar perusahaan dapat menghemat biaya. Memuat atribut eksterior gerai yang menarik

\section{Pengolahan Data Game Theory}

\begin{tabular}{lcc}
\hline \multirow{2}{*}{ Atribut pada Permainan } & \multicolumn{2}{c}{ Variabel yang digunakan } \\
\cline { 2 - 3 } & Alfamart & Indomaret \\
\hline Product & $\mathrm{SA}_{1}$ & $\mathrm{SI}_{1}$ \\
Price & $\mathrm{SA}_{2}$ & $\mathrm{SI}_{2}$ \\
Promotion & $\mathrm{SA}_{3}$ & $\mathrm{SI}_{3}$ \\
Place & $\mathrm{SA}_{4}$ & $\mathrm{SI}_{4}$ \\
People & $\mathrm{SA}_{5}$ & $\mathrm{SI}_{5}$ \\
Process & $\mathrm{SA}_{6}$ & $\mathrm{SI}_{6}$ \\
Physical Evidence & $\mathrm{SA}_{7}$ & $\mathrm{SI}_{7}$ \\
\hline
\end{tabular}

sumber: data primer diolah, 2021

Pengolahan data game theory disajikan pada tabel berikut berdasarkan ouput POM-QM for windows sehingga diperoleh hasil sebagai berikut:

Tabel 2. Matriks Nilai Perolehan Alfamart dan Indomaret

\begin{tabular}{l|lllllll}
\hline & Y1 & Y2 & Y3 & Y4 & Y5 & Y6 & Y7 \\
\hline X1 & 2 & 0 & 24 & 18 & 18 & 18 & 14 \\
X2 & 8 & 14 & 0 & 4 & 18 & 12 & 6 \\
X3 & 20 & 32 & 22 & 26 & 14 & 30 & 12 \\
X4 & 10 & 2 & 16 & 18 & 24 & 22 & 26 \\
X5 & 8 & 10 & 10 & 20 & 10 & 22 & 8 \\
X6 & 4 & 0 & 34 & 6 & 24 & 16 & 16 \\
X7 & 4 & 14 & 22 & 14 & 20 & 18 & 22 \\
\hline
\end{tabular}

sumber: data primer diolah, 2021

Penghitungan maksimin untuk pemain baris dan minimin untuk pemain kolom untuk menentukan strategi yang akan digunakan.

Tabel 3. Hasil Nilai Teori Permainan untuk Strategi Murni

\begin{tabular}{c|cccccccc}
\hline & Y1 & Y2 & Y3 & Y4 & Y5 & Y6 & Y7 & Min \\
\hline X1 & 2 & 0 & 24 & 18 & 18 & 18 & 14 & 0 \\
X2 & 8 & 14 & 0 & 4 & 18 & 12 & 6 & 0 \\
X3 & 20 & 32 & 22 & 26 & 14 & 30 & 12 & $\begin{array}{c}12 \\
\text { (maksimin) }\end{array}$
\end{tabular}




\begin{tabular}{c|cccccccc} 
X4 & 10 & 2 & 16 & 18 & 24 & 22 & 26 & 2 \\
X5 & 8 & 10 & 10 & 20 & 10 & 22 & 8 & 8 \\
X6 & 4 & 0 & 34 & 6 & 24 & 16 & 16 & 0 \\
X7 & 4 & 14 & 22 & 14 & 20 & 18 & 22 & 4 \\
Max & $\begin{array}{l}22 \\
\text { (minimaks) }\end{array}$ & 32 & 34 & 26 & 24 & 30 & 26 & \\
\hline
\end{tabular}

Dari Tabel 3, nilai maksimin yaitu 12 tidak sama dengan nilai minimaksnya yaitu 22 artinya permainan tidak bisa diselesaikan dengan menggunakan strategi murni. Langkah selanjutnya menyelesaikan dengan menggunakan strategi campuran.

Tabel 4. Hasil Nilai Permainan untuk Strategi Campuran

\begin{tabular}{c|cccccccc}
\hline & Y1 & Y2 & Y3 & Y4 & Y5 & Y6 & Y7 & $\begin{array}{c}\text { Row } \\
\text { Mix }\end{array}$ \\
\hline X1 & 2 & 0 & 24 & 18 & 18 & 18 & 14 & 0 \\
X2 & 8 & 14 & 0 & 4 & 18 & 12 & 6 & 0 \\
X3 & 20 & 32 & 22 & 26 & 14 & 30 & 12 & 0,67 \\
X4 & 10 & 2 & 16 & 18 & 24 & 22 & 26 & 0,33 \\
X5 & 8 & 10 & 10 & 20 & 10 & 22 & 8 & 0 \\
X6 & 4 & 0 & 34 & 6 & 24 & 16 & 16 & 0 \\
X7 & 4 & 14 & 22 & 14 & 20 & 18 & 22 & 0 \\
Column mix & 0,58 & 0 & 0 & 0 & 0 & 0 & 0,42 & \\
$\begin{array}{c}\text { Value of game } \\
\text { (to row) }\end{array}$ & 16,67 & & & & & & & \\
\hline Sumber: data primer diolah, 2021 & & & & & & & &
\end{tabular}

Sumber: data primer diolah, 2021

Dari hasil perolehan strategi campuran didapatkan output value of game (to row) sebesar 16,67 yang artinya pemain baris dalam permainan lebih unggul dari pemain kolom. Selanjutnya adalah menentukan strategi apa yang maksimal diterapkan Alfamart untuk memaksimalkan keuntungan dan strategi apa yang maksimal diterapkan Indomaret untuk meminimalisir kerugian yang didapat yaitu dengan menggunakan strategi yang menghasilkan column mix dan row mix lebih tinggi, yaitu strategi product dan promotion.

Tabel 5. Hasil Nilai Permainan untuk Strategi Campuran

\begin{tabular}{c|cc}
\hline & Y1 & Y3 \\
\hline X1 & -6 & 24 \\
X3 & 20 & 22 \\
\hline \multicolumn{2}{l|}{ sumber: data primer diolah, 2021}
\end{tabular}

Dari hasil matriks perolehan selanjutnya dilakukan kembali penghitungan maksimin untuk pemain baris dan minimin untuk pemain kolom untuk menentukan strategi yang akan digunakan. 
Tabel 6. Hasil Nilai Permainan untuk Strategi Campuran

\begin{tabular}{c|ccc}
\hline & Y1 & Y3 & Min \\
\hline X1 & -6 & 24 & -6 \\
X3 & 20 & 22 & 20 \\
Max & $\begin{array}{c}20 \\
\text { (minimaks) }\end{array}$ & 24 & \\
sumber: data primer diolah, 2021 &
\end{tabular}

Dari Tabel 6. terlihat bahwa nilai maksimin yaitu 20 sama dengan nilai minimaksnya yaitu 20 artinya permainan sudah selesai.

Tabel 7. Hasil Nilai Permainan untuk Strategi Campuran

\begin{tabular}{c|ccc}
\hline & Y1 & Y3 & Row mix \\
\hline X1 & -6 & 24 & 0 \\
X3 & 20 & 22 & 1 \\
Column mix & 1 & 0 & \\
\cline { 2 - 3 } 2021 & &
\end{tabular}

Pemain baris mendapatkan angka 1 pada strategi promosi yang artinya Alfamart untuk memaksimalkan keuntungannya menggunakan strategi produk. Pesaingnya yaitu pemain kolom mendapatkan angka 1 pada strategi produk, yang artinya Indomaret untuk meminimumkan kerugian yang didapatkan dari persaingan menggunakan strategi promosi. Keterangan: baris merupakan strategi Alfamart dan kolom merupakan strategi Indomaret.

\section{Penutup dan Saran}

\section{Simpulan}

Berdasarkan hasil analisis data melalui Importance Performance Analysis, didapatkan bahwa Kuadran I dengan tingkat kepentingan tinggi namun kepuasan yang didapatkan pelanggan masih rendah (strategi yang harus ditingkatkan), memuat keterjangkauan harga; kesesuaian harga dengan kualitas produk; kesesuaian harga dengan manfaat. Kuadran II dengan tingkat kepentingan dan kepuasan yang dirasakan tinggi oleh pelanggan (merupakan faktor yang harus tetap dipertahankan). Memuat produk yang lengkap jenisnya, produk yang ditawarkan sesuai standar karena telah lolos uji BPOM, produk yang beragam mereknya sesuai dengan kebutuhan pelanggan, poin untuk member; keragaman media untuk promosi; diskon atau obral, akses yang mudah dijangkau, ketersediaan tempat parkir, lokasi dekat dengan tempat beraktivitas, pelayanan yang dilakukan karyawan ramah, sopan, cepat tanggap dan akurat, penempatan barang yang mudah dicari, pencahayaan dan sirkulasi udara yang baik, proses pelayanan yang cepat, ketersediaan fasilitas debit card.

Berdasarkan hasil yang telah diuji strategi promosi Alfamart melalui Game Theory menunjukkan bahwa nilai strategi pemasaran pada Alfamart dengan strategi promotion (promosi) jauh lebih besar jika dibandingkan dengan strategi pemasaran yang ditawarkan oleh Indomaret dengan strategi product (produk). 


\section{Saran}

Penulis menyadari bahwa penelitian ini masih jauh dari kata sempurna. Penulis berharap penelitian selanjutnya lebih menyempurnakan hasil penelitian ini yang tentunya merujuk pada hasil penelitian yang sudah ada dengan harapan supaya penelitian yang dihasilkan dapat lebih baik dari sebelumnya. Saran untuk penelitian selanjutnya adalah perlu diteliti lebih spesifik lagi pelanggan yang benar-benar menjadi pelanggan pada Alfamart dan Indomaret di Kebumen atau bahkan ritel lainnya. agi peneliti diharapkan penelitian ini dapat dimanfaatkan dengan sebaik mungkin untuk rujukan penelitian selanjutnya yang berhubungan dengan sistem pemasaran dalam perusahaan.

\section{Referensi}

Abbas, F. (2015). Pengaruh Marketing Mix Terhadap Kepuasan Konsumen (Pada Home Industry Moshimoshi Cake Samarinda). E-Journal Administrasi Bisnis, 3(1), 224-258.

Adam, M. (2018). Manajemen Pemasaran Jasa Teori dan Aplikasi. (I. Fahmi, Penyunt.) Bandung, Jawa Barat, Indonesia: Penerbit Alfabeta.

Gultom, D. K., Ginting, P., \& Sembiring, B. K. (2014). Pengaruh bauran pemasaran jasa dan kualitas pelayanan terhadap kepuasan mahasiswa program studi manajemen fakultas ekonomi universitas muhammadiyah sumatera utara. Jurnal Ilmiah Manajemen dan Bisnis, 14(1)., 21-33.

Gumiwang, R. (2019, April Selasa). Alfamart vs Indomaret: Siapa Lebih Pesat? Diambil kembali dari tirto.id: https:/ / tirto.id/alfamart-vs-indomaret-siapa-lebih-pesat-dlvo

Kotler, P. (2003). Manajemen Pemasaran. Edisi Kesebelas, Jakarta: Indeks Kelompok Gramedia.

Kotler, P., \& Keller, K. L. (2009). Manajemen Pemasaran Jilid 1 Edisi ke 13. Jakarta: Erlangga.

Lupiyoadi, R., \& Hamdani, A. (2009). Manajemen Pemasaran Jasa (2 ed., hal. 81-82). Jakarta: Penerbit Salemba Empat.

Ma'ruf, H. (2005). Pemasaran Ritel. Jakarta: Gramedia Pustaka. Pemasaran Ritel. Jakarta: Gramedia Pustaka.

Sunyoto, D. (2015). Manajemen Bisnis Ritel. Yogyakarta: CAPS Center for Academic Publishing Service.

Tjiptono, F., \& Diana, A. (2016). Pemasaran Esensi \& Aplikasi. Yogyakarta: Penerbit Andi.

Yuni, S. M., Rusdiana, S., \& Isnardi, I. (2018). Strategi Pemasaran Warung Kopi di Kota Banda Aceh dengan Game Theory. Journal of Data Analysis, 1(2), 49-63. 